\title{
C) HitșTórica
}

\section{O positivismo e as mulheres no carnaval de Porto Alegre nas primeiras décadas do século XX}

\author{
Positivism and women in the Porto Alegre carnival in the first decades of the 2oth \\ century
}

Caroline P. Leal"

Resumo: O carnaval de Porto Alegre, no início do século XX, - representado pelas sociedades carnavalescas Esmeralda e Venezianos - é marcado por transformações que podem ser entendidas através da ótica dos estudos de gênero. De Evas pecadoras, as mulheres passaram a figurar como Marias, recatadas e redentoras. O presente artigo busca discutir as razões para a transformação na participação das mulheres nesse festejo, a partir da influência do positivismo e de sua apropriação em Porto Alegre pela elite da capital, através da existência de redes de poder que envolviam a participação de membros do Exército Brasileiro, da Brigada Militar do Rio Grande do Sul e dos quadros do Partido Republicano Riograndense nas tradicionais sociedades carnavalescas.

Palavras-chave: relações de gênero, carnaval, positivismo.

Abstract: Porto Alegre' Carnival, at the beginning of the twentieth century, is represented by Emerald and Venetians, through transformations that can be understood from the perspective of gender studies. From sinful Evas, as women, they became Marias, modest and redeeming. The present on the way of human women, in the case of the end of human women, in the case of a power of involved in Portugal of elite, the Military Brigade of Rio Grande do Sul and the cadres of the Riograndense Republican Party in the carnival societies.

Keywords: gender relations, carnival, positivism.

"Doutora em História/Pontifícia Universidade Católica do Rio Grande do Sul/CAPES. 
O início da década de I870, em Porto Alegre, é marcado por uma intensa campanha jornalística de combate às brincadeiras de entrudo ${ }^{2}$. Considerado um jogo bárbaro, grosseiro e licencioso deveria ser substituído por uma forma civilizada, moderna e decorosa de se comemorar os dias de Momo: o carnaval veneziano3. Desta forma, em I873, surge em Porto Alegre a Sociedade Carnavalesca Esmeralda e a Sociedade Carnavalesca Os Venezianos. Nesse novo carnaval as mulheres perderiam seus espaços: protagonistas nas brincadeiras de entrudo - tanto mulheres da elite, quanto de classes populares -, no carnaval veneziano, deveriam assistir e aplaudir aos desfiles promovidos pelos homens das referidas agremiações. Embora tenham feito sucesso, Esmeralda e Venezianos se retirariam da, ainda no século XIX, e entre os motivos apresentados para a falência, estava a insistência do público feminino na prática entrudesca. Os Venezianos, em seu programa para o carnaval do ano de I882, enfatizavam a permanência da "perniciosa bisnaga" e o fato de elas "emanarem de delicadas e alvas mãozinhas" " ${ }^{4}$ que continuavam a contaminar o carnaval. Eram as Evas a pecar no paraíso!

Com o desaparecimento das tradicionais agremiações e o aparecimento de novas formas de brincar a festa - que passou a ser promovida por outros sujeitos, não pertencentes às elites da cidade -, a imprensa da capital demonstrava um grande descontentamento com o festejo. $\mathrm{O}$ jornal $O$ Independente alertava para uma "licenciosa libertinagem que vai aos poucos corrompendo a nossa juventude, em uma ameaça feroz e real às bases sacratíssimas do lar, à moral da família que é o fundamento do edifício social. Todas essas considerações vêm a propósito de festa pagã e lúbrica do carnaval." 5

No início do século XX, contudo, as sociedades carnavalescas Esmeralda e Venezianos ressurgiriam nos festejos carnavalescos da cidade de Porto Alegre. Essa nova fase foi marcada por modificações no que tange à participação das mulheres. Além da ampliação dos espaços, ocupados pelas mulheres no carnaval, proposto pelas referidas

\footnotetext{
${ }^{2} \mathrm{O}$ entrudo foi a maneira pela qual o carnaval chegou ao Brasil, através de nossos colonizadores portugueses. Consistia no arremesso de limões de cheiro (esferas de cera em formato de laranjas/limão que continham água perfumada), água jogada de bisnagas, seringas, bacias e baldes, farinha, pó de arroz e vermelhão. O objetivo era mesmo molhar e sujar o adversário. A licenciosidade, contudo, era um dos principais argumentos de críticas ao entrudo e motivo para que as sociedades carnavalescas o enterrassem de vez. O velho jogo "dá[va] ao belo sexo o delírio das bacantes" ${ }^{2}$, como afirmava Xicolomã, cronista do jornal A Reforma. A Reforma, Porto Alegre, I8 de fevereiro de I 875.

${ }^{3}$ No Rio de Janeiro, na segunda metade do século XIX, surgiu a primeira Grande Sociedade Carnavalesca. Fundada pela elite cariosa, saía em cortejo nas ruas com fantasias luxuosas, ao estilo do carnaval europeu. José de Alencar, sócio fundador das Sumidades Carnavalesca, escreveu no do Jornal Gazeta Mercantil de I855 que "ao invés do passeio pelas ruas da cidade, os mascarados da Sumidades iriam se reunir do Passeio Público e lá iriam passar uma tarde da mesma forma como se passa uma tarde de carnaval na Itália, jogando confetes, distribuindo flores e intrigando com suas máscaras conhecidos e amigos"(FERREIRA, 2005).

${ }^{4}$ Jornal do Commercio, Porto alegre, I8 de fevereiro de I882).

${ }_{5} \mathrm{O}$ Independente, Porto Alegre, 9 de março de 1905.
} 
agremiações, se observa que houve mudanças na representação das carnavalescas. As mulheres que participavam da festa passaram a ser louvadas por seus comportamentos irrepreensíveis e por sua conduta moral, livrando a cidade daquela concupiscência deflagrada na virada do século. Neste sentido, as rainhas das sociedades carnavalescas ocuparam especial lugar, se tornando modelos de virtude e beleza, figurando como Marias nos festejos promovidos por Esmeralda e Venezianos ${ }^{6}$.

Num primeiro momento, portanto, as mulheres participavam apenas como espectadoras e embelezadoras da festa promovida por Esmeralda e Venezianos. Figuraram como uma das causas do fracasso do carnaval por serem as maiores entusiastas com a perniciosa brincadeira do entrudo. Porém, ao renascerem Esmeralda e Venezianos, passaram a organizar os festejos burlescos e, acima de tudo, representavam a figura do bom carnaval, da moral e bons costumes, a representação da regeneração moral do carnaval. O que teria provocado essa mudança no discurso, tanto da imprensa, quanto das próprias sociedades carnavalescas, que passara a exaltar a ativa participação feminina, atribuindolhes o reerguimento e a nova feição do carnaval? Quais seriam as razões para essa glorificação das mulheres na nova fase dessas agremiações? Mulheres que antes eram criticadas por se entregarem ardorosamente à festa passaram a ser enaltecidas por isto? Por que as mulheres passaram de Evas a Marias?

O presente artigo busca apresentar a apropriação do ideário positivista pela elite local como um dos motivos para a transformação da participação das mulheres no carnaval de Porto Alegre. Buscarei mostrar que, com participação de membros da elite política e militar nos quadros destas associações, se teceram redes de poder que ajudam a entender o processo de genderização da festa.

\section{A Porto Alegre de Clotilde de Vaux}

Na virada do século XIX para o XX, momento marcado pela ausência de Esmeralda e Venezianos, se percebia na imprensa porto-alegrense um grande descontentamento com o tipo de festa carnavalesca que estava sendo feita na cidade. Declarações de que o carnaval

\footnotetext{
${ }^{6}$ No carnaval de 1909, a sociedade Esmeralda comparava a sua rainha a Nossa Senhora em versos que eram distribuídos à população durante seu préstito: "Vai passar a Rainha - a nossa Grã Senhora,Virgem Nossa Senhora Imaculada e Casta - qual a santa de um ádro, ao resplendor da aurora,Ou qual mago Santélmo a quem o mar se afasta!/Virgem Nossa Senhora Aparecida em vasta, Nuvem d'ouro e de sonho a qual o sol rubora, Virgem Santa Maria, a cujos pés se arrasta, A multidão que geme e a Sua Graça implora.../Virgem Santa do Céu! Como ela é bela e moça, E como, feito d'alma, o seu olhar se adoça, E se expande e se estende e sobre nós se reflora! /Ei-la!... Deixem passar o seu ardor singelo! Abram alas!... Avante, ó devotos do belo: Vai passar a Rainha - a Nossa Grã Senhora!" A Federação, Porto Alegre, 2I de fevereiro de 1909.
} 
era uma festa cada vez mais plebeia, mais abjeta, altamente imoral e que se devia zelar pela moral pública ${ }^{7}$. A fim de atingir o progresso, a organização e regeneração moral da sociedade se fazia importante. E se o carnaval de Porto Alegre era sintomático de uma "sífilis social" era preciso uma festa que a livrasse desse mal.

Dessa forma, a partir do renascimento de Esmeralda e Venezianos, a moralidade passou a ser a tônica dos discursos proferidos pela imprensa, bem como sinal de distinção do carnaval da cidade De acordo com o jornal Correio do Povo, "Porto Alegre é uma exceção. Seu Carnaval é um ressumbramento de arte e galanteria, de elegância e moralidade" 9. E, talvez por esse motivo, nessa nova fase, o jornal $O$ Independente destacasse que "durante os três dias de carnaval a rua dos Andradas encontrava-se cheia de famílias"Io.

Outro argumento utilizado para enaltecer o carnaval, após o retorno de Esmeralda e Venezianos e que justificaria a sua superioridade moral, seria o fato do povo ter aprendido a apreciar os festejos com o devido comedimento: “o poviléu não se desmanda na expansão de suas alegrias; não se excede, porque já se acostumou a essa espécie de domínio que a virtude exerce do alto $^{\text {II }}$ O povo já não mais transgredia às ordens em função do carnaval, já havia compreendido que seu papel era apreciar a festa oferecida por Esmeralda e Venezianos: seu entusiasmo com o reinado de Momo era "todo respeitoso e discreto, pois que, representando uma divindade mitológica ou um herói contemporâneo, um pugilo de amazonas ou um esquadrão de média idade, - o povo vê passar a donzela encantadora e gentil portadora de um nome respeitado, o cavalheiro qualificado, o escol da sociedade indígena" I2.

Através da Religião da Humanidade, Auguste Comte pregava a necessidade de uma nova crença pautada pela a elevação moral do homem e, neste sentido, as mulheres tiveram papel fundamental. Segundo Silva (2004, p. Io) se defendia a reforma da sociedade a partir da formação moral e do caráter a ser ensinado "desde os primeiros anos da criança, devendo ser tarefa da família, especialmente da mulher como a primeira educadora, a valorização das primeiras manifestações do altruísmo na criança". Ao considerar a mulher como a responsável pela manutenção da moral, Comte conferiu "modelos de conduta feminina baseados na mentalidade patriarcal, formada ao longo da História da Humanidade" (ISMÉRIO, 2005, p. 158). Para atingir esses modelos, a "mulher deveria ser a rainha do lar e

\footnotetext{
${ }^{7} \mathrm{O}$ Independente, Porto Alegre, o9 de março de 1905.

${ }^{8} \mathrm{O}$ Independente, Porto Alegre, o9 de março de 1905.

9 Correio do Povo, Porto Alegre, io de fevereiro de íı.

Io O Independente, Porto Alegre, I2 de março de 1908.

${ }^{\text {II }}$ Correio do Povo, Porto Alegre, Io de fevereiro de i9io.

${ }^{12}$ Correio do Povo, Porto Alegre, io de fevereiro de i9io.
} 
o anjo tutelar de sua família” (ISMÉRIO, 2005, p. I58) e, assim, seguir a normas preestabelecidas pelo Catecismo Positivista, no qual "Comte codificou todo o pensamento conservador em torno da mulher" (ISMÉRIO, 2005, p. I58).

Na doutrina elaborada por Comte, a mulher era o gênero que melhor representaria o altruísmo - único a fornecer a base para a convivência social na nova sociedade sem Deus, daí ser ela o símbolo ideal para a humanidade, que vinha em primeiro lugar na escala de valores positivistas (CARVALHO, I995, p. 8I). Contudo, "apesar da grande ênfase no papel feminino, apesar da declaração da superioridade da mulher sobre o homem" (CARVALHO, I995, p. 8I), Comte acabava atribuindo "o papel tradicional de mãe e esposa, de guardiã do lar, pois era assim que a mulher garantia a reprodução da espécie e a saúde moral da humanidade" (CARVALHO, I995, p. 93). Para ele, "na preservação da espécie, o papel da mulher não se limitaria a reprodução, mas se daria especialmente na família, em que, como mãe, ela teria a responsabilidade da formação moral do futuro cidadão" (CARVALHO, I995, p. 93).

Esse modelo de mulher, mãe, esposa responsável pela saúde moral da sociedade foi proposto por Comte, inspirado em Clotilde de Vaux, jovem que conheceu e por quem se apaixonou. Nascida em abril de I8I5, veio a falecer em maio de I846 - dois anos após o encontro com Comte. Iniciaram uma amizade amorosa que "transmudou-se em uma paixão sublimada" (SOARES, 1998, p. 74), haja vista Clotilde ser ainda casada com Amadeo de Vaux. Essa paixão ficou restrita à adoração platônica e Comte, já amadurecido "em suas ideias quanto à indissolubilidade do vínculo matrimonial no regime monogâmico, à proibição do divórcio e à viuvez eterna, chegou à conclusão de que o afeto entre ambos deveria oferecer à posteridade uma imagem de inalterável pureza" (SOARES, I998, p. 75). Foi Clotilde quem despertou em Comte um melhor conhecimento da natureza feminina e, "após sua morte prematura, conduzi-o ao caminho do crescente aperfeiçoamento moral, necessário para construir a segunda parte de sua obra" (SOARES, I998, p. 75). Assim, é a partir de seu encontro com Clotilde que se dá o que ele chamou de sua regeneração moral. A musa de Comte "tornou-se a representação da mulher ideal, considerando-a íntegra, pura, perfeita. Isso ocorreu porque o filósofo nunca a tocou, tornando-a símbolo de adoração com atributos herdados do arquétipo da Grande Mãe" (ISMÉRIO, 2005, p. I59).

O modelo da Grande Mãe tinha sua antítese representada por Caroline Massin. Antes de conhecer Clotilde, Comte casou-se com Caroline, "uma prostituta, com quem teve uma relação bastante conflituosa" (ISMÉRIO, 2005, p. 159), vindo a separar-se dela quase vinte 
anos após o casamento. De acordo com Ismério (2005, p. I59), "a primeira foi moldada a partir do arquétipo de Maria, A Virgem, e a segunda no de Eva, A Pecadora”.

Se, por um lado, as mulheres que permaneceram jogando o entrudo em Porto Alegre foram culpabilizadas pelo fim do carnaval venezianos, simbolizando Evas, a pecar no paraíso, ou até mesmo, Caroline Massin; por outro, no momento de renascimento dessas agremiações, elas seriam as Marias do carnaval, a personificação de Clotilde de Vaux. Desta forma, foi atribuído às mulheres um importante papel na tarefa de regeneração moral do carnaval de Porto Alegre. O jornal Correio do Povo exultava o culto à mulher e à reforma que estavam a executar em prol da regeneração da festa:

E é realmente belo de ver-se e edificante de sentir-se, esse culto da Mulher, quando o inspiram sentimentos de alegria sã e quando em torno de almas de arminho.

Porque a verdade é esta: entre nós, e por honra nossa, o Carnaval quase que completamente deixou de ser a folia pagã na convulsão dos gozos profanos, exaustivos, e sim um pretexto para desafogarem-se os espíritos das amarguras e do tédio do diuturno viver afanoso e volverem-se, numa ânsia de consolação e de alegre remanso, para as mil formas de endeusamento do sexo que é flor de ideal atração ${ }^{13}$.

Livrando Porto Alegre da folia pagã e dos gozos profanos, as mulheres passaram a figurar como elemento de regeneração moral das festas carnavalescas, nesse renascer esmeraldino e venezianos. Assim como a família, o carnaval passara a ser uma instituição em que se primava por uma educação carregada pela formação moral e de responsabilidade feminina, afinal "era a linda, a grácil Mulher porto-alegrense que fazia o Carnaval. Por isso vinha ele tão garboso, tão gentil e tão chic. Por isso tinha sido possível o milagre de sua ressurreição"I4.

As jovens rainhas das sociedades carnavalescas, filhas de famílias importantes e conhecidas da cidade - "a donzela encantadora e gentil portadora de um nome respeitado" -tiveram especial função na representação da regeneração moral do carnaval de Porto Alegre. Solteiras, entre doze e dezenove anos, exaltadas por sua beleza, graça, candura, fineza, instrução, modéstia e dotes morais, nenhuma outra mulher era mais exaltada do que elas no carnaval. Para as rainhas eram dedicados bailes, tea concerts, exposições de seus

\footnotetext{
${ }^{13}$ Correio do Povo, Porto Alegre, Io de março de 1908.

${ }^{14}$ Correio do Povo, Porto Alegre, 17 de fevereiro de 1907.
} 
retratos, vários eventos que pretendiam consagrar a soberana da agremiação. Por meio do carnaval se difundia o ideal de uma mulher que deveria ser: bonita, mas ingênua; culta, mas modesta; elegante e, sobretudo, moralizada. Essa imagem era veiculada não somente pela fala, como também nas fotografias que eram tiradas das rainhas e expostas nas vitrines das principais ruas da cidade, disponível aos olhos de todos! Eram as Marias o símbolo do carnaval!

Todavia, se em Porto Alegre essas donzelas eram a figura central do carnaval, "em outros grandes centros as festas de Carnaval são a consagração das hetairas da flor e do vício" "I5. No Rio de Janeiro, nos desfiles de suas tradicionais sociedades, as mulheres apareciam como forte atração popular, sobretudo, a partir da década de I870. Entretanto, as mulheres que desfilavam eram célebres meretrizes ou as "hetairas da flor e do vício" e não "as boas moças de família”, as "donzelas de um nome respeitado" do carnaval portoalegrense. Seus préstitos traziam “'deusas' pouco vestidas e expondo ao público aquelas mulheres de luxo - inacessíveis aos bolsos populares, mas provavelmente frequente em suas fantasias" (CUNHA, 20oI, p. I47). O carnaval tido como mais familiar, no qual não eram prostitutas a desfilar, só se daria nas menores sociedades carnavalescas, dos subúrbios cariocas, nas quais a presença de moças de família era comum (CUNHA, 200I, p. I47).

Em Porto Alegre, no início da década de I870, uma polêmica sobre a proibição do jogo do entrudo ganhou as páginas de dois importantes periódicos da capital gaúcha - A Reforma e o Riograndense ${ }^{I 6}$. No cerne da discussão estava o protagonismo de Maria Isabel de Sousa Alvim, esposa do Presidente da Província do Rio Grande do Sul, Antonio da Costa Pinto e Silva, nas brincadeiras de entrudo. Acusada de se fazer reviver o jogo, foi moralmente atacada pelo jornal A Reforma: "Que esta renovação do passado fosse obra da ex-marquesa nada há que admirar, pois é muito conhecida pelo seu ardente temperamento e extraordinário calor" ${ }^{7}$.

Em trabalho anterior (LEAL, 2008) trabalhei com a hipótese de se comparar o comportamento da ex-marquesa de Monte Alegre ao de uma hetera ateniense. Na Grécia Antiga, o termo hetairai era utilizado para designar as mulheres que acompanhavam os homens no espaço público. Segundo Ullmann (2005, p.64), "eram mulheres de alguma cultura e não raras provindas do estrangeiro. Participavam em pé de igualdade nas

\footnotetext{
${ }^{15}$ A Federação, Porto Alegre, 20 de fevereiro de 1912.

${ }^{16}$ O jornal A Reforma foi fundado em I862 em Porto Alegre por Gaspar da Silveira Martins e Antônio Eleutério de Camargo. Foi o órgão oficial do Partido Liberal gaúcho. Já o Riograndense era o jornal oficial do Partido Conservador e oficial do governo (FRANCO, 2006).

${ }^{17}$ A Reforma, Porto Alegre, I5 de fevereiro de I87I.
} 
conversações com os homens que eventualmente se valiam delas para satisfação sexual". Essas mulheres podiam participar dos simpósios, festividades das quais as mulheres casadas não podiam. Enquanto esposas, se restringiam apenas ao espaço do gineceu.

Por esse motivo, a imprensa nos apresentou uma ex-marquesa com um comportamento condizente ao de uma hetera. Vinda de fora, de São Paulo, ela jogou o entrudo e em espaço público, participando em pé de igualdade com os homens da festividade. É preciso, contudo, explicar que a ex-marquesa era uma mulher casada, diferenciando-se, nesse sentido, das heteras atenienses, embora tenha sido atacada pelo jornal A Reforma no que se refere à sua atitude de liberdade de agir, de forma semelhante aos homens, rompendo com os lugares a ela destinados.

Décadas após o ocorrido com a ex-marquesa, encontrei o jornal Correio do Povo utilizando o mesmo adjetivo para designar as mulheres que participavam das festas carnavalescas em outros lugares, como vimos acima. A ex-marquesa teve um comportamento liberal e foi classificada tal qual as "hetairas da flor e do vício", por não corresponder à adequação dos modelos culturais que passaram a ser relacionados ao comportamento feminino no que tange as festividades carnavalescas.

Outros episódios de participação de mulheres que não correspondiam a tais expectativas geraram a indignação da imprensa: no carnaval de I900, por exemplo, o Jornal do Comércio noticiava o escândalo que provocava a "'patriótica horizontal' que, em carro aberto acompanhada de outras três prostitutas, desfilava no carnaval de 1900 pela rua dos Andradas empunhando a bandeira nacional" ${ }^{18}$. O desfile desta 'patriótica horizontal' deve ter provocado um verdadeiro alvoroço, sobretudo, por a moça empunhar a bandeira nacional, verdadeiro bastião dos positivistas, a quem a moral social era tão cara. Ou ainda, durante o carnaval de 1904, no qual duas mulheres teriam desfilado "anunciando sua mercadoria”, de forma clara e evidente. Chamadas de 'pestes' pelo jornal A Federação estavam disfarçadas apenas pelo vestuário multicor, que dava uma reabilitação exterior, mas que tinha como principal consequência o fato de tornar essas mulheres mais valiosas no mercado do sexo.

Agora é um carro de tolda caída, com a clássica colcha de renda dependurada (...).

Sentadas a sultana vão duas mulheres de meia máscara, uma à moda tunisina e outra em trajes de pescadora. Para bem dizer nenhuma delas

${ }^{18}$ Jornal do Comércio, Porto Alegre, 28 de fevereiro de 1900. 
representa tipo algum. Arranjaram-se, simplesmente, de modo que pudessem anunciar a sua mercadoria com toda a clareza e evidência.

Talvez vão ali duas pestes, mas o vestuário multicor e espaventoso reabilita-as exteriormente.

Vejam lá como se encostam, hein, olhem que vamos todas de sedas e pedras finas e não admitimos brincadeiras pesadas. E já se sabe que daqui por diante valemos mais ${ }^{19}$.

De acordo com Sandra Pesavento (1995, p.62), o crescimento do centro urbano da cidade passou a oferecer ameaça à moral e aos bons costumes das famílias honradas. Estas famílias tiveram que conviver com habitantes que "viviam na 'contramão da ordem instituída e que apresentavam comportamentos desviantes daqueles que a moral burguesa procurava impor", como por exemplo, os bêbados, jogadores, vagabundos e as prostitutas. Tal incômodo era evidenciado pelos jornais que apresentavam um desagrado com a participação das prostitutas nos festejos carnavalescos da cidade, bem como com sua presença em suas principais ruas.

Entre todas as práticas atentatórias à moral e aos bons costumes nenhuma outra atraíra "contra si uma campanha tão acirrada como a prostituição" (PESAVENTO, 1995, p. 67). Ela era condenada "por ser atentatória aos bons costumes, por ser uma forma de vadiagem, negadora do trabalho e ainda por se achar associada a todos os demais vícios da urbe: jogos, bebidas, etc" (PESAVENTO, I995, p. 67). Além disso, era um comportamento que "se afastava dos padrões e elementos componentes da virtude" (CARELI, 2005, p. I56), tão cara à moral social. A mulher que se prostituía e com isso apresentava uma conduta desregrada ao "afrontar os parâmetros estabelecidos pelo ordenamento social, servia como exemplo a ser condenado pelas famílias, pois apesar de considerada, em tese, profissão, paradoxalmente a prostituição não comportava a noção de trabalho que os detentores do capital criaram" (PESAVENTO, I995, p. 67).

Havia um temor em relação ao contágio associado à prostituição. Contaminação tanto da parte física, quanto moral da sociedade. Os cronistas reivindicavam à polícia medidas cerceadoras, pois a presença de mulheres em locais públicos, lugares "nos quais as tascas se constituíam, era tida como fonte de desordens e de ações lesivas à moral da comunidade" (CARELI, 2005, p.I67). "Felizmente, acabaram os grosseiros e brutais Zés-

${ }^{19}$ A Federação, Porto Alegre, I7 de fevereiro de 1904. 
Pereiras, mas surgiram dos becos para a Rua dos Andradas as horizontais de ínfima classe"20, reclamava A Federação, em I9Io. Desta forma, de nada adiantaria regulamentar a prostituição, ao invés de acabar com o problema, o que "ampliaria os riscos de alargar-se e contaminar ainda mais os indivíduos social, física e moralmente" (CARELI, 2005, p. 176).

Os acontecimentos descritos acima reforçam a ideia de que o ressurgimento das antigas sociedades veio em respaldo a uma tentativa de moralização da festa. A figura da rainha, cheia de graça, pureza e imaculada, contrastava com a imagem dessas mulheres, que exibiam os corpos, até mesmo como forma de propaganda de seu negócio, como exaltou o jornal A Federação. Se o comportamento daquelas era exaltado, o destas era criticado: seriam pestes a contaminar a cidade.

O diferencial do carnaval de Porto Alegre após o renascimento de Esmeralda e Venezianos, desta forma, passa a ser a moralidade. De acordo com A Federação "formamos um carnaval típico, que não se confunde com nenhum outro, e que tem o aspecto de uma festa de família sem as etiquetas dos salões nobres, mas também sem os excessos e a nudez chocante do carnaval carioca e parisiense ${ }^{21}$.

Contudo, por mais que este carnaval moralizado e familiar fosse exaltado, encontramos, mesmo após o renascer das tradicionais sociedades, agremiações que se pautavam mais pelo modelo de carnaval da capital do país, do que pelo que aqui era apregoado como correto e sinal de distinção dos nossos festejos. No ano de 1907, a sociedade Boêmios Carnavalescos trouxe algumas mulheres da vida noturna para seu desfile. Nos anúncios de jornal, convidavam as "gentilíssimas ninfas" para seus bailes à fantasia ${ }^{22}$, no qual "Rir e folgar - mulheres e champagne, eis o nosso ideal", aparecia como lema. Esse comportamento, provavelmente, não era bem aceito, haja vista não haver nenhuma referência ao episódio, tanto no jornal A Federação, quando no Jornal do Comercio. Lazzari já acentuava que "a repercussão da proeza parece ter sido convenientemente abafada pela imprensa, de forma que pouco se sabe a respeito desta sociedade e do que realmente aconteceu além de rumores posteriores ao fato" (LAZZARI, 200I).

Em 1971, Walter Spalding escreveu um artigo no jornal Correio do Povo, intitulado "No tempo dos limões de cheiro e das batalhas de flores", no qual faz uma rememoração sobre os antigos carnavais porto-alegrense. Segundo ele, os Boêmios Carnavalescos estavam ligados ao Clube Cara Duras e "contra qual a imprensa reclamou veementemente. É que seus carros

\footnotetext{
${ }^{20}$ A Federação, Porto Alegre, 20 de fevereiro de i9ıo.

${ }^{21}$ A Federaçẫo, Porto Alegre27 de fevereiro de I9II.

${ }^{22}$ Correio do Povo, Porto Alegre, o9 de fevereiro de 1907.
} 
alegóricos e todos os participantes femininos pertenciam à vida noturna, o que muito escandalizou a sociedade"23. A presença das prostitutas nos desfiles de carnaval era um incômodo para a elite, sobretudo, se durante os dias de carnaval não fossem as "honradas moças da terra" que estivessem a se exibir nos carros e sim as "moças da vida".

Joan Scott, ao propor o gênero - o saber a respeito das diferenças sexuais, "um elemento constitutivo de relações sociais fundadas sobre as diferenças percebidas entre os sexos, e [...] o primeiro modo de dar significados às relações de poder" (SCOTT, 1990, p.I5) como uma categoria de análise histórica, elenca quatro aspectos fundamentais de análise: os símbolos, os conceitos normativos, uma noção de política e referências às instituições bem como a organização social e pôr fim a identidade subjetiva.

O carnaval é uma festa repleta de simbologia, na qual os signos "culturalmente disponíveis que evocam representações simbólicas" (SCOTT, I990, p.I4) se fazem presentes a todo instante. As representações simbólicas invocadas em seus contextos específicos permitem que percebamos os símbolos de modo dicotômico, antipodal: tais signos estão carregados de juízos de valor e se aplicam à figura feminina. As mulheres, de acordo com seu comportamento - percebido como adequado ou não em determinado contexto histórico -, são rotuladas como Evas ou Marias, purificadas ou poluídas, inocentes ou corrompidas (SCOTT, I990, p.I4). Nesse sentido, observamos que, durante os festejos carnavalescos em Porto Alegre, as atitudes femininas podiam ser louvadas e reverenciadas pelos jornais ou recriminadas com acusações em torno da moralidade e da licenciosidade.

No que se refere aos conceitos normativos, "expressos nas doutrinas religiosas, educativas, científicas, políticas ou jurídicas" (SCOTT, 1990, p. I4), entendo que a mudança nas estruturas políticas brasileiras - a partir do final do Império e início da República e a instauração, no Rio Grande do Sul, de um governo que, como veremos, foi fortemente inspirado em um positivismo difuso - influenciou nessa transformação das relações de gênero e dos espaços e lugares ocupados pelas mulheres nos festejos carnavalescos. Isso se deve ao fato de que o modelo de carnaval aqui estudado - representado, principalmente, pelas sociedades Esmeralda e Venezianos - foi idealizado no final do século XIX, ainda no período do Império, tendo desaparecido quase que ao mesmo tempo em que esse regime político. Quando ocorreu o ressurgimento dessas duas sociedades - já sob a República e com o Partido Republicano Rio-Grandense (PRR) ocupando a presidência do estado percebemos uma mudança no que se refere às práticas e lugares ocupados pelas mulheres

${ }^{23}$ Correio do Povo, Porto Alegre, 2I de fevereiro de I97I. 
durante os festejos, tendo a participação das mulheres sofrido a mediação dos ideais de mulher difundidos pelo castilhismo e sua interpretação do pensamento positivista, bem como as diretrizes do catolicismo no Brasil (LEAL, 20I3, p. II6-I34). Esses conceitos normativos que "tomam a forma típica de uma oposição binária, que afirma de maneira categórica e sem equívocos o sentido do masculino e do feminino" (SCOTT, 1990, p. I4), permitem-nos, ainda, por "em evidência as interpretações do sentido dos símbolos, que se esforçam para limitar e conter suas possibilidades metafóricas” (SCOTT, I990, p. I4), possibilitando-nos enxergar como “a história posterior é escrita como se estas posições normativas fossem produto de um consenso social mais do que um conflito" (SCOTT, I990, p. I5), pois

quando as(os) historiadoras(es) buscam encontrar as maneiras pelas quais o conceito de gênero legitima e constrói as relações sociais, elas(es) começam a compreender a natureza recíproca do gênero e da sociedade e as maneiras particulares e situadas dentro de contextos específicos, pelas quais a política constrói o gênero, e o gênero constrói a política (SCOTT, I990, p. I6).

Em 1906, ano do renascimento de Esmeralda e Venezianos, Porto Alegre era governada por José Montaury (PRR), já em seu terceiro mandato. Nascido no Rio de Janeiro, em I858, "formou-se engenheiro pela Escola Politécnica, onde recebeu grande influência da filosofia positivista" (BAKOS, 1996, p. 48). Homem de confiança de Júlio de Castilhos estava no comando da cidade desde I897 (FRANCO, 2006).

O Partido Republicano Riograndense (PRR) foi fundado em 23 de fevereiro de I882, sendo fortemente influenciado pela filosofia de Comte ${ }^{24}$. De acordo com Margaret Bakos (I998, p. I), “encontramos no Rio Grande do Sul, na prática política dos administradores do estado, um empenho extraordinário em governar a partir dos princípios desenvolvidos por Augusto Comte". Desta forma, quando se dá o ressurgimento de Esmeralda e Venezianos, Porto Alegre estava politicamente identificada com os ideais positivistas de governo, moldados pelo PRR.

Tratava-se, todavia, de um positivismo que teve apropriado apenas uma parte de seu conjunto, seu espírito cientificista e - embora em menor proporção - sua teoria religiosa. Para Cruz Costa (1967, p. I27), o positivismo teria chegado ao Brasil sob os auspícios da "nova burguesia" em ascensão, em contraposição aos interesses tradicionais dos latifundiários que

${ }^{24}$ Entre os fundadores do Partido Republicano Riograndense (PRR) se encontra Ramiro Barcellos, presidente da sociedade Esmeralda em I883. 
dominavam o cenário político de então. Esse novo grupo - composto por médicos, militares e engenheiros -, a partir de I870, teria assumido papel de importância no setor intelectual brasileiro, e a partir dele que surgiria o movimento positivista. No Rio Grande do Sul, sobressaiu-se uma vertente mais claramente política, tendo como símbolo máximo a figura de Júlio de Castilhos, que passou pelas fileiras da Escola Politécnica do Rio de Janeiro (LINS, I964, p. 64).

Nelson Boeira (200I, p. 40I), ao estudar o positivismo riograndense, afirma que o "impacto do comtismo no Rio Grande do Sul não se restringiu às esferas da política e da religião", tendo impactado, igualmente, várias áreas da vida intelectual. As ideias positivistas foram absorvidas, de uma forma ou de outra, por uma multiplicidade de públicos que as difundiram, as desviaram e as deformaram. A influência da simbologia extraída de Comte, não se limitou aos projetos político-institucionais. Esse positivismo difuso, que não pode ser entendido como fruto direto de Augusto Comte, se fez presente também na esfera carnavalesca. As analisar as festas de Esmeralda e Venezianos - a partir de seu renascimento, em 1906 - veremos que há uma série de significados que correspondem a doutrina inspiradora do partido que governava o Estado e sua capital. Essa correspondência é evidente no que tange a participação das mulheres nos festejos, ao tornar a regeneração moral da sociedade (e do carnaval) uma tarefa a ser desempenhada pelas mulheres; bem como a relação entre o catolicismo e a experiência positivista que se consolidava em Porto Alegre.

Além disso, posso afirmar que havia uma reciprocidade entre as elites políticas e os quadros dessas agremiações: grande parte dos associados e diretores fazia parte das elites do PRR. Bruneilde Fontoura, diretora dos Venezianos em 1906, era filha de Idelfonso Borges Toledo da Fontoura, positivista religioso, que era professor da escola de Engenharia (HEINZ, 2009). Manuel Teófilo Barreto Vianna, presidente da Esmeralda em I9Io e I9II, foi eleito para a assembleia dos representantes do estado pelo PRR entre os anos de I89I e I897 (TRINDADE; NOLL, 2005). Idalina Mariante da Costa, rainha da Esmeralda em I9I3, casouse, dois anos mais tarde, com Mansueto Bernardi, membro do PRR que, em I9I8, no lançamento da pedra fundamental do edifício da Sociedade Carnavalesca Gondoleiros, representou o próprio presidente do estado, Borges de Medeiros, na cerimônia ${ }^{25}$. Amaro de Azambuja Vilanova, que fazia parte da Comissão Central da Esmeralda no ano de seu primeiro desfile, fez carreira no Exército, tendo sido designado interventor federal de

${ }^{25}$ Correio do Povo, Porto Alegre, 12 de março de 1918. 
Pernambuco, em 1937, por Getúlio Vargas, de quem era amigo íntimo. Vilanova foi o primeiro general de quatro estrelas do Brasil (CAMARGO, I989, p. 222).

Além do PRR, outra instituição que sofreu forte influência do positivismo-castilhismo foi a Brigada Militar do Rio Grande do Sul (BMRS). Força policial de segurança pública do estado, foi criada em I892 e era uma instituição forjada na "observância da disciplina e da hierarquia, com base nos valores da guerra tudo cimentado pelo positivismo castilhista" (KARNIKOWSKI, 20I0, p.96). Afonso Emílio Massot, comandante geral da Brigada Militar entre os anos de I9I7 e I925 e patrono da instituição era um "castilhista convicto". A intensa ligação entre o governo do estado e a Brigada reforçava "o cimento da corporação que acreditava na superioridade moral dos militares que sabemos ser uma variante do positivismo muito forte nos oficiais castilhistas" (KARNIKOWSKI, 20IO, p.I92). Para Karnikovski (20I0, p. 192), "a bem dizer todos os oficiais da Brigada Militar eram castilhistas até a década de 40, quando a influência do 'Patriarca Republicano' começa a declinar dentro da milícia". O autor prossegue ao enfatizar que o "positivismo em seu discurso da ordem e do progresso sob o signo da ciência, se constituiu na principal argamassa ideológica dos oficiais da Brigada Militar, além de ser o sacramento que fundamentava o regime castilhistaborgista" (KARNIKOWSKI, 20IO, p.I92). A importância de se observar a influência do positivismo-castilhismo sobre os quadros da BMRS reside no fato de grande parte dos membros e diretores de Esmeralda e Venezianos estar ligada a corporação: o próprio Afonso Emílio Massot será presidente da Venezianos em vários anos (1909, I912 e 1913).

Assim como BMRS, o Exército Brasileiro também era um bastião da ideologia Comteana. Segundo Frank McCann (2007, p.40), o corpo de oficiais do Exército Brasileiro provinha de famílias sem muitos recursos, que aconselhavam os filhos a ingressarem em uma das três escolas militares do país, no Rio de Janeiro, em Porto Alegre ou em Fortaleza. O coronel Benjamin Constant, professor de matemática, foi o principal expoente da filosofia positivista dentro das escolas e do exército.

Desta forma, é interessante ressaltar que grande parte das rainhas das sociedades carnavalescas eram filhas de militares, seja da BMRS ou do Exército Brasileiro: Themira de Azevedo, rainha da Venezianos em 1908, era filha de Amphilóquio de Azevedo, tenentecoronel do estado maior ${ }^{26}$ e professor da Escola de Guerra ${ }^{27}$; Laura Brasil Paes, rainha da

\footnotetext{
${ }^{26}$ Promoção de Amphilóquio do Azevedo, major do quadro especial do estado-maior, a tenente do coronel o do estado maior. Diário Oficial [da República Federativa do Brasil], Rio de Janeiro, or de outubro de I9I2. 27 "Código do Instituto oficiais de ensino superior e secundário aprovado pelo decreto n. 3.800 de $\mathrm{I}^{\mathrm{O}}$ de abril de I90I, e 286 do regulamento que baixou com o do n. 330 do I2 de abril de I890, ao professor da Escola de Guerra tenente-coronel Amphilóquio de Azevedo e acréscimo do 20 sobre os vencimentos lixados para aquele cargo,
} 
esmeralda em 1909, era filha do coronel Miguel de Oliveira Paes ${ }^{28}$; Amelina Chagastelles, rainha da Esmeralda em I9Io, era filha de Joaquim Pantaleão Teles Queiros Filho, primeiro Comandante-Geral da recém-criada Brigada Militar do Rio Grande do Sul, em I892 ${ }^{29}$; Elythia, rainha da Sociedade Carnavalesca Esmeralda, em I9II, era filha de João Leocádio Pereira de Melo $^{30}$, comandante Tenente-coronel, desde I894 $4^{31}$, diretor do arsenal de guerra ${ }^{32}$; Marina de Souza Neves, rainha da Esmeralda em I9I4, era filha de Arthur Pinto de Souza Neves, tenente do Estado maior ${ }^{33}$. Ao considerarmos que, grande parte dos integrantes das sociedades carnavalescas faziam parte dos quadros, tanto da Brigada Militar, quanto do Exército Brasileiro, corrobora-se a evidência da presença do positivismo, mesmo que de modo difuso, na maneira de se ver e fazer o carnaval.

Outro indício dessa influência pode ser percebido a partir da utilização de um jargão positivista pelo jornal Correio do Povo, para comentar o baile promovido pela Esmeralda, em 1908. Ao descrever o baile, o periódico afirmou que "à meia noite ouviu-se a palavra de ordem: 'máscaras abaixo'. E realmente era de justiça que se tratasse, quanto antes, de viver às claras no seio de uma sociedade tão nobre e que é verde...”34. Verde era a cor da Esmeralda e viver às claras era uma máxima do positivismo. De acordo com Bosi (VER ANO, p. 158), “o ethos comteano levava ao ideal de uma sociedade onde predominassem os valores de verdade e transparência: viver às claras, vivre au grand jour". O Correio do Povo ratificava a ideia de superioridade moral dos membros da Esmeralda, fazendo um trocadilho com as máscaras usadas no baile carnavalescos e as máscaras da vida: máscaras abaixo.

Em 1907, no primeiro préstito realizado pela Esmeralda, após seu renascimento, o Jornal do Comércio noticiava que Benjamin Flores - um dos membros do movimento de restauração da S. C. Esmeralda, eleito secretário da agremiação nesse ano35 - "o cônsul do

\footnotetext{
o qual ser-lhe-ha abonado a contar de 28 de abril último, visto haver completado na véspera desse dia 20 anos de serviço no magistério". Diário Oficial [da República Federativa do Brasil], Rio de Janeiro, I8 de setembro de I909, p. 3.

${ }^{28}$ Diário Oficial [da República Federativa do Brasil], Rio de Janeiro, I8 de dezembro de I900, p.2.

${ }^{29}$ RIO GRANDE DO SUL (ESTADO). Assembleia Legislativa do Rio Grande do Sul, 92a Sessão Ordinária, I8 de Novembro de 2004. Disponível em

https://web.archive.org/web/200602IOI52039/http://www.al.rs.gov.br/plen/SessoesPlenarias/visualiza.asp?ID_ $\underline{\text { SESSAO }=247}$.

30 O Independente, Porto Alegre, 22 de janeiro de igiı.

${ }^{31}$ Promoção do tenente-coronel João Leocádio Pereira de Mello a comandante. Diário Oficial [da República Federativa do Brasil], Rio de Janeiro, I6 de Junho de I90I, pg.I. Ele também foi comandante do IO ${ }^{\circ}$ Batalhão de Engenharia de Construção, entre dezembro de I895 e março de I898.

${ }^{32}$ A Federação, Porto Alegre, 2I de fevereiro de I9Io.

33 Diário Oficial [da República Federativa do Brasil], Rio de Janeiro, 25 de julho de I909, p.5.

34 Correio do Povo, Porto Alegre, II de fevereiro de 1908.

${ }^{35}$ ATA da S. C. Esmeralda. Instituto Histórico Geográfico do Rio Grande do Sul, Porto Alegre, 25 de fevereiro de 1907 .
} 
deus Momo, junto á Esmeralda, trajará costume de gala civil, colete e gravata da cor do positivismo, tendo na mão direita o sagrado bastão e na sinagoga a coroa, lapidada em alto relevo... ${ }^{30 " . ~ T a l ~ d e s c r i c ̧ a ̃ o ~ a p o n t a, ~ n o v a m e n t e, ~ p a r a ~ a ~ e s t r e i t a ~ r e l a c ̧ a ̃ o ~ e n t r e ~ o s ~ i d e a i s ~}$ positivistas e a referida agremiação e seus membros, uma vez que, os indivíduos que se pensam e se visualizam como membros de uma coletividade, acabam por expressar símbolos que apregoam valores, medos, aspirações dos os ideais em que acreditam.

\section{Conclusão}

Procurei demonstrar que o carnaval de Porto Alegre, no início do século XX, representado pelas sociedades carnavalescas Esmeralda e Venezianos - foi marcado por transformações que podem ser entendidas através da ótica dos estudos de gênero. De Evas, entrudeiras, pecadoras; as mulheres passaram a figurar como Marias, rainhas, recatadas e redentoras.

A busca por explicações para essa transformação deve levar em conta que o ressurgimento das tradicionais sociedades carnavalescas se dá em um momento posterior à implementação do regime republicano no país - trazendo consigo um conjunto de mudanças significativas e, no Rio Grande do sul, a ascensão de um partido político ideologicamente orientado pelo comtismo-castilhismo. Como capital do Estado do Rio Grande do Sul, Porto Alegre "gozava de uma importância singular pelo papel desempenhado na consolidação da hegemonia do Partido Republicano Rio-Grandense (PRR)” (BAKOS, I996, p. I3). Muitos sócios de Esmeralda e Venezianos também pertenciam aos quadros do partido.

Além disso, a ativa participação dos militares no carnaval de Porto Alegre, a influência do positivismo castilhista, tanto na Brigada Militar do Rio Grande do Sul, quanto do Exército Nacional, e a crença na "superioridade moral dos militares" (KARNIKOWSKI, 20I0, p.I92.) podem, de certo modo, explicar as modificações ocorridas nos festejos carnavalescos na capital. Mesmo que, nem todos os membros dessas agremiações pudessem "ser definidos como 'positivistas' em sentido doutrinário, a maioria compartilhava uma série de códigos culturais impregnados por aquilo que Nelson Boeira classificou como positivismo político e positivismo difuso" (Apud HEINZ, 2009, p. 03).

A moral social era um dos caros princípios do positivismo e o renascimento das tradicionais sociedades promoveria, aos olhos da imprensa, uma regeneração moral dos

\footnotetext{
${ }^{36}$ Jornal do Comercio, Porto Alegre, I4 de fevereiro de I907.
} 
festejos carnavalescos. Aos moldes da doutrina que estava a inspirar, essa tarefa foi delegada às mulheres. A presença das filhas de oficiais da BMRS e do Exército nos desfiles e a expectativa moral que era gerada sobre pessoas tão ilustres em nossa sociedade, podem nos dar indícios deste carnaval mais recatado, proporcionado por essas sociedades, e que tornaram as Marias o símbolo do carnaval de Porto Alegre.

\section{Referências Bibliográficas}

BAKOS, Margaret. Marcas do positivismo no governo municipal de Porto Alegre. Estud. av., São Paulo, v. I2, n. 33, 1998.

BAKOS, Margaret. Porto Alegre e seus Eternos Intendentes. Porto Alegre: EDIPUCRS, 1996.

BOEIRA, Nelson. O Rio Grande de Augusto Conte. IN: O Positivismo - Teoria e Prática. Porto Alegre: Editora da UFRGS, $200 I$.

BOSI, Alfredo. O positivismo no Brasil: uma ideologia de longa duração. In: Do positivismo à desconstrução: idéias francesas na América [S.l: s.n.], 2004.

CALEIRO, R. C. L o Positivismo e o Papel das Mulheres na Ordem Republicana. UNIMONTES CIENTÍFICA. Montes Claros, v.4, n.2, jul./dez. 2002.

CAMARGO, Aspásia. et al. O golpe silencioso: as origens da república corporativa. Rio de Janeiro: Rio Fundo, 1989.

CARELI, Sandra. Mulheres no Brasil Meridional. Prostituição em fins do século XIX: transgressão ou delito? Ciênc.let., Porto Alegre, n.37, p.I55-I77, jan/jun. 2005.

CARVALHO, José Murilo de. A formação das almas: o imaginário da República no Brasil. $2^{\mathrm{a}}$ ed. São Paulo: Companhia das Letras, 1995.

COSTA, C. Contribuição à História das Ideias no Brasil. Rio de Janeiro: Ed. Civilização Brasileira, 1967.

CUNHA, Maria C. P. Ecos da Folia: uma história social do carnaval carioca entre I880 e 1920. São Paulo: Companhia das Letras, 200I.

FERREIRA, Felipe. O livro de ouro do carnaval brasileiro. Rio de Janeiro: Ediouro, 2005.

FRANCO, Sérgio da Costa. Guia Histórico de Porto Alegre. Porto Alegre: Editora da Universidade (UFRGS), 2006.

HEINZ, Flavio M. Positivistas e republicanos: os professores da Escola de Engenharia de Porto Alegre entre a atividade política e a administração pública (I896-I930), Rev. Bras. Hist. vol.29 no. 58, São Paulo, 2009. 
KARNIKOWSKI, Romeu Machado. De exército estadual à polícia-militar: o papel dos oficiais na policialização da Brigada Militar (I892-I988). Tese de Doutorado. Porto Alegre: UFRGS/PPGSoc, 2010.

LEAL, Elisabete. Castilhos e Honorina: fragmentos biográficos sem cartas de amor. MÉTIS: história \& cultura, p. I09-I27.

LEAL, Caroline P. As Mulheres no Reinado de Momo: Lugares e Condições Femininas no Carnaval de Porto Alegre. Dissertação de Mestrado, PPGH/PUCRS, Porto Alegre, 2008.

LINS, I. História do Positivismo no Brasil. São Paulo: Companhia Editora Nacional, I964.

MCCANN, Frank D. Soldados da Pátria - História do Exército brasileiro I889-I937. São Paulo: Cia das Letras, 2007.

PESAVENTO, Sandra. O Cotidiano da República: elite e povo na virada do século. Porto Alegre: Ed. Da Universidade/UFRGS, 1995.

SILVA, João Carlos. Utopia Positivista e instrução pública no Brasil. Revista HISTEDBR Online, Campinas, n.I6, p. I0 - I6, dez. 2004.

SOARES, Mozart Pereira. O positivismo no Brasil: 200 anos de Augusto Comte. Porto Alegre: Editora AGE, 1998.

TRINDADE, Hélgio; NOLL, Maria Izabel. Subsídios para a história do Parlamento Gaúcho (I890-I937). Porto Alegre: CORAG, 2005.

ULLMANN, Reinholdo. Amor e Sexo na Grécia Antiga. Porto Alegre: EDIPUCRS, 2005.

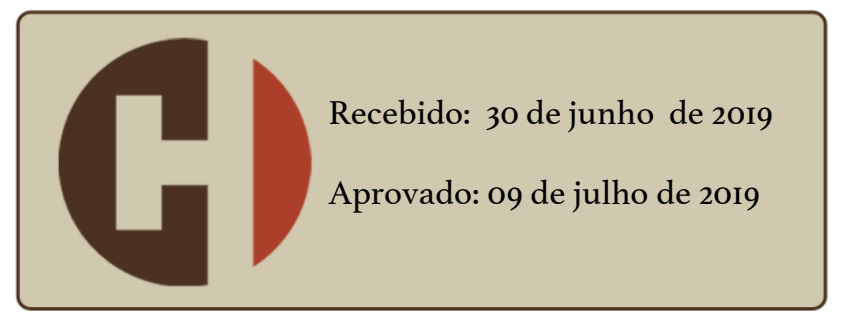

